\title{
Grey Correlation Analysis on the Economic Factors of Regional Logistics in Guangdong Province
}

\author{
Weiguo $\mathrm{Li}^{1}$, Xiaoying Zhong ${ }^{2}$, Xiaorong $\mathrm{Wu}^{3 *}, \mathrm{Na} \mathrm{Ye}^{4}$ \\ ${ }^{1234}$ Business School, Nanfang College of Guangzhou, 510970, Conghua District of Guangzhou, China
}

\begin{abstract}
Taking the regional logistics of Guangdong Province as the research object, this paper uses the relevant data of logistics and economy of Guangdong Province from 2015 to 2019, and applies the grey correlation analysis method to study the correlation degree between the relevant indicators of economic development of Guangdong Province and the development level of regional logistics. Through quantitative calculation, it clearly shows the relevant economic factors that have a greater impact on regional logistics, and provides good suggestions and Countermeasures for the healthy development of regional logistics.
\end{abstract}

\section{INTRODUCTION}

Logistics system is a subsystem of social economic system, which plays a very important role in regional economic system. With the acceleration of the process of regional economic integration, the relationship between regional logistics and regional economy has become more and more close. The development of regional economy will promote the demand market of regional logistics and the development of regional logistics. Regional logistics is an important part of regional economy, which will provide a good platform for the development of regional economy and promote the rapid development of regional economy. The regions with more developed regional economy tend to have more developed logistics industry and strong logistics demand, and vice versa.

Regional logistics demand refers to the requirements of space, time, workload and cost of goods generated by the allocation of raw materials, finished products and semi-finished products, used goods and waste materials in the fields of production, circulation and consumption by social and economic activities in a certain period of time and within a certain region, involving transportation, warehousing, packaging, loading and unloading and handling Circulation processing and related information processing and other aspects of logistics activities. There are two kinds of indicators to measure regional logistics demand: one is the entity system indicators, such as freight volume, freight turnover, inventory, processing volume. The second is the value system indicators, such as transportation, warehousing and other logistics costs, total logistics costs, the proportion of logistics costs in GDP, total logistics revenue.

According to the "Iceberg Theory", the logistics system itself is a gray system, with obvious randomness and uncertainty. The relationship between regional economy and regional logistics is constantly changing.
The economic factors affecting regional logistics have obvious timeliness. The data collected are the data of recent years. This is a small sample problem, and the information reflected is not comprehensive enough, with gray characteristics. Therefore, in the study of the relationship between regional logistics and regional economy, it is suitable to use grey correlation analysis method to compare the relationship between the two. This paper uses this method to quantitatively analyze the relationship between regional logistics and various economic indicators in Guangdong Province, and puts forward some opinions and suggestions, which has certain practical significance for the scientific and reasonable development of regional logistics in Guangdong Province.

\section{Literature review}

With the increasingly fierce competition in regional economy, the impact of regional logistics on regional economy is becoming more and more important. The rapid development of regional economy promotes the continuous increase of regional logistics demand and the continuous improvement of regional logistics efficiency, which can better promote the healthy development of regional economy.

In foreign countries, the research on the direct relationship between regional logistics and regional economy is earlier. Heehoo ham and others believe that the development of regional economy is affected by the unexpected events in the process of physical flow between regions, and make a quantitative analysis of the relationship by building a mathematical model ${ }^{[1]}$; Donald J. Bowersox studied the interaction between regional logistics and regional economy ${ }^{[2]}$. The results show that regional economy and logistics industry influence and promote each other; Macuilis qualitatively analyzes the relationship between logistics infrastructure investment

*Xiaorong Wu: 24587605@qq.com 
and economic growth, clarifies the positive and negative effects of logistics infrastructure investment on economic growth, and puts forward feasible strategies for coordinated growth between the two ${ }^{[3]}$.

Many domestic scholars use grey correlation method to analyze the correlation between regional logistics and regional economy. Xiao Jing and Dong Qingxue used the grey correlation analysis method to analyze the correlation degree between freight turnover and regional economic indicators in Jilin Province, and put forward reasonable suggestions to promote the development of regional logistics according to the order of correlation degree from high to low ${ }^{[4]}$. Gao Sheng and Zhang Xifeng studied the relative economic factors which have important influence on the regional logistics of Zhejiang Province through the grey correlation method, and provided some suggestions for the development of regional logistics ${ }^{[5]}$. Rong Luqing constructs the influencing factors system from the aspects of regional economy, regional logistics environment, industrial development and informatization, and uses gray correlation analysis to analyze the relevant factors affecting the waterway freight volume. ${ }^{[6]}$ These scholars have applied the grey correlation method to analyze the factors that have great influence on regional logistics, and put forward some suggestions. For the development of regional logistics in Guangdong, the grey correlation analysis method has not been applied to study the relevant economic factors.

\section{Research Methods}

Grey relational analysis is a quantitative analysis method for the development and change trend of a system. Its basic idea is to determine whether they are closely related by determining the geometric similarity of a reference sequence and several comparison sequences ${ }^{[7]}$. It reflects the degree of correlation between curves. The calculation steps of grey correlation analysis method are as follows.

Let $\mathrm{n}$ data form the following matrix

$$
\left(X_{1}^{\prime}, X_{2}^{\prime} \cdots, X_{n}^{\prime}\right)=\left(\begin{array}{cccc}
x_{1}^{\prime}(1) & x_{2}^{\prime}(1) & \cdots & x_{n}^{\prime}(1) \\
x_{1}^{\prime}(2) & x_{2}^{\prime}(2) & \cdots & x_{n}^{\prime}(2) \\
\vdots & \vdots & \vdots & \vdots \\
x_{1}^{\prime}(m) & x_{2}^{\prime}(m) & \cdots & x_{n}^{\prime}(m)
\end{array}\right)
$$

Where $\mathrm{m}$ is the number of indicators

$$
X_{i}^{\prime}=\left(x_{i}^{\prime}(1), x_{i}^{\prime}(2), \cdots, x_{i}^{\prime}(m)\right)^{T}, \quad i=1,2, \cdots, n
$$

Step 1: determine the reference sequence

$$
X_{0}^{\prime}=\left(x_{0}^{\prime}(1), x_{0}^{\prime}(2), \cdots, x_{0}^{\prime}(m)\right)
$$

Step 2: dimensionless processing of comparative sequence data

The measurement units of each series data in the system are inconsistent. When the grey correlation analysis is carried out, the direct comparison will produce large errors. Generally, it is necessary to deal with the data of each sequence dimensionless, and the initial value method is used to do dimensionless processing.

$$
\begin{array}{r}
x_{i}(k)=\frac{x_{i}^{\prime}(k)}{x_{i}^{\prime}(1)} \\
i=0,1, \cdots, n ; \quad k=1,2, \cdots, m .
\end{array}
$$

Step 3: calculate absolute value

Calculate the absolute difference between each index sequence (comparison sequence) and the corresponding element of reference sequence one by one.

$$
\text { That is } \triangle \mathrm{i}=\left|x_{0}(k)-x_{i}(k)\right|
$$

(number of objects evaluated)

Step 4: determine the maximum and minimum difference

$$
\begin{array}{r}
\Delta \min =\min _{i=1}^{n} \min _{k=1}^{m}\left|x_{0}(k)-x_{i}(k)\right| \\
\Delta \max =\max _{i=1}^{n} \max _{k=1}^{m}\left|x_{0}(k)-x_{i}(k)\right|
\end{array}
$$

Step 5: calculate the correlation coefficient

The correlation coefficients of each comparison sequence and the corresponding elements of reference sequence are calculated respectively.

$$
\begin{gathered}
\zeta_{i}(k)=\frac{\min _{i} \min _{k}\left|x_{0}(k)-x_{i}(k)\right|+\rho \cdot \max _{i} \max _{k}\left|x_{0}(k)-x_{i}(k)\right|}{\left|x_{0}(k)-x_{i}(k)\right|+\rho \cdot \max _{i} \max _{k}\left|x_{0}(k)-x_{i}(k)\right|} \\
k=1, \cdots, m
\end{gathered}
$$

In the above formula $\rho$ For resolution coefficient, value between $(0,1)$, if $\rho$ The smaller the correlation coefficient, the greater the difference, the stronger the ability of differentiation, usually 0.5 .

Step 6: calculate the association order

The mean value of correlation coefficient between each index and the corresponding elements of reference sequence is calculated for each evaluation object (comparison sequence), so as to reflect the correlation relationship between each evaluation object and reference sequence, and call it the correlation order, and record it as

$$
r_{0 i}=\frac{1}{m} \sum_{k=1}^{m} \zeta_{i}(k)
$$

\section{Empirical Analysis}

\subsection{Selection of regional logistics economic factors in Guangdong Province}

There are many evaluation indexes of regional logistics development level in Guangdong Province. Based on the existing research, from the perspective of data availability, rationality and representativeness, the whole social freight volume is usually used to represent the regional logistics development demand. Relevant data of 2015-2019 are collected from the statistical yearbook of Guangdong Province 2020, and the data of the designed freight volume (10000 tons) is $\mathrm{x} 0$; The regional gross product (billion yuan) is set as X1; The turnover of goods (100 million tons $\mathrm{km}$ ) is set to $\mathrm{x} 2$; The GDP of the third industry (billion yuan) is set to $\mathrm{X} 3$, and the data of transportation, storage and postal transportation (billion 
yuan) is set to $\mathrm{X} 4$; The total import and export amount (billion yuan) is set to $\mathrm{X} 5$; The mileage $(\mathrm{km})$ of the highway is set to $\mathrm{X} 6$, and the following table 1 is obtained.

\subsection{Data collection and grey correlation calculation of regional logistics influencing factors}

Table 1. Regional logistics development index of Guangdong Province from 2015 to 2019

\begin{tabular}{|c|c|c|c|c|c|}
\hline Year & 2015 & 2016 & 2017 & 2018 & 2019 \\
\hline $\mathrm{X}_{0}$ & 349832 & 377645 & 400601 & 424996 & 446018 \\
\hline $\mathrm{X}_{1}$ & 74732.44 & 82163.22 & 91648.73 & 99945.22 & 107671.07 \\
\hline $\mathrm{X}_{2}$ & 14667.43 & 22032.27 & 28192.23 & 28644.77 & 29230.88 \\
\hline $\mathrm{X}_{3}$ & 37628.92 & 43163.49 & 49500.68 & 54710.37 & 59773.38 \\
\hline $\mathrm{X}_{4}$ & 2662.73 & 2877.45 & 3166.69 & 3363.48 & 3466.42 \\
\hline $\mathrm{X}_{5}$ & 63559.70 & 63099.68 & 68168.86 & 71645.73 & 71484.39 \\
\hline $\mathrm{X}_{6}$ & 216023 & 218085 & 219580 & 217699 & 220290 \\
\hline
\end{tabular}

Data source: Guangdong statistical yearbook 2020

Step 1: Obtain the following sequence after dimensionless processing of data sequence

$\mathrm{X} 0^{\prime}=\{1.0000,1.0795,1.1451,1.2149,1.2749\}$
$\mathrm{X} 1^{\prime}=\{1.0000,1.0994,1.2264,1.3374,1.4408\}$
$\mathrm{X} 2^{\prime}=\{1.0000,1.5021,1.9221,1.9530,1.9929\}$
$\mathrm{X} 3^{\prime}=\{1.0000,1.1471,1.3155,1.4539,1.5885\}$
$\mathrm{X} 4^{\prime}=\{1.0000,1.0806,1.1893,1.2632,1.3018\}$
$\mathrm{X} 5^{\prime}=\{1.0000,0.9928,1.0725,1.1272,1.1247\}$
$\mathrm{X} 6^{\prime}=\{1.0000,1.0095,1.0165,1.0078,1.0198\}$

Step 2, find the difference sequence

The following difference sequence is obtained according to formula (5)

$\Delta 01=\{0.0000,0.0199,0.0812,0.1225,0.1658\}$

$\Delta 02=\{0.0000,0.4226,0.7770,0.7381,0.7180\}$

$\Delta 03=\{0.0000,0.0676,0.1704,0.2391,0.3135\}$

$\Delta 04=\{0.0000,0.0011,0.0441,0.0483,0.0269\}$

$\Delta 05=\{0.0000,0.0867,0.0726,0.0876,0.1503\}$

$\Delta 06=\{0.0000,0.0700,0.1287,0.2071,0.2552\}$

Step 3, which can be obtained from the above results

$\Delta \min =0, \Delta \max =0.7770$

Step 4, calculate the correlation coefficient

According to the calculation of formula 3-8, the table 2 correlation coefficient table is obtained

Table 2. Correlation coefficient table

\begin{tabular}{|c|c|c|c|c|c|}
\hline Year & 2015 & 2016 & 2017 & 2018 & 2019 \\
\hline$\xi_{01}$ & 1.0000 & 0.9512 & 0.8271 & 0.7602 & 0.7009 \\
\hline$\xi_{02}$ & 1.0000 & 0.4790 & 0.3333 & 0.3448 & 0.3511 \\
\hline
\end{tabular}

\begin{tabular}{|c|c|c|c|c|c|}
\hline$\xi_{03}$ & 1.0000 & 0.8518 & 0.6951 & 0.6190 & 0.5534 \\
\hline$\xi_{04}$ & 1.0000 & 0.9971 & 0.8980 & 0.8894 & 0.9353 \\
\hline$\xi_{05}$ & 1.0000 & 0.8175 & 0.8425 & 0.8159 & 0.7211 \\
\hline$\xi_{06}$ & 1.0000 & 0.8474 & 0.7512 & 0.6523 & 0.6035 \\
\hline
\end{tabular}

Step 5: customs clearance joint sequence

Calculate the association order according to formula 9

$$
\begin{aligned}
& \gamma_{01}=0.8479, \gamma_{02}=0.5016, \gamma_{03}=0.7439, \\
& \gamma_{04}=0.9439, \gamma_{05}=0.8394, \gamma_{06}=0.7709
\end{aligned}
$$

From large to small order by association order

$$
\gamma_{04}>\gamma_{01}>\gamma_{05}>\gamma_{06}>\gamma_{03}>\gamma_{02}
$$

\section{Conclusions and Suggestions}

From the above-mentioned correlation order, the economic factors which have great influence on the regional logistics and freight volume in Guangdong Province are traffic, storage and postal transportation volume $>$ regional GDP $>$ total import and export amount $>$ road mileage $>$ tertiary industry gross output value $>$ goods turnover. The above research shows that the first three factors that affect the regional logistics development are traffic, storage and postal transportation, regional GDP and total import and export, and the three indicators which have weak influence on the development are road traffic process, the total output value of the third industry and the turnover of goods. The results show that regional logistics is closely related to regional economic development, developed regional economy, rapid increase of logistics demand, promotion of logistics operation efficiency and rapid development of regional logistics; The rapid development of regional logistics has increased new impetus for regional economy, which is conducive to improving infrastructure construction and accelerating the rapid development of local economy. Therefore, they are mutually influential, mutually advancing and developing together.

The first three grey correlation order values are larger, all of which exceed 0.8 , which indicates that the transportation volume, regional GDP and total import and export volume of transportation, warehousing and postal transportation have great influence on the logistics and freight volume of Guangdong Province. The two indicators, the mileage of highway traffic and the total output value of the tertiary industry, are above 0.7 , which indicates that the two indicators have a great influence on regional logistics. Only the last index of goods turnover has a weak influence on regional logistics, with the value of about 0.5 .

The following suggestions are put forward in combination with the above analysis.

Firstly, the logistics development of Guangdong Province is closely related to the level of local economic development. Guangdong has maintained the first level of economic development for 23 years in a row, and the high-speed economic development level has produced great logistics demand. Therefore, the local logistics 
development speed is leading in the country. From the above analysis, it is found that the impact of transportation, post and transportation on regional logistics development is very important. It is necessary to strengthen and improve the infrastructure construction constantly, increase investment in highway, railway, aviation, port and other traffic infrastructure and post and telecommunications communication equipment, and promote the construction and improvement of logistics facilities. On the basis of the existing development, we will continue to improve.

Secondly, the total import and export of Guangdong Province has reached more than $20 \%$ in the whole country for many years. The huge import and export demand has greatly promoted the development of international logistics and played a great role in the development of Guangdong logistics. The mileage of highway opening to traffic is closely related to the logistics development level of Guangdong Province. In 2020, Guangdong Province will achieve 10000 kilometers of high-speed mileage, and realize the county county expressway, which lays a solid foundation for the smooth development of logistics in the province. In the future, we still need to continue to increase investment in these areas and maintain high-speed development.

Thirdly, in recent years, Guangdong has been committed to industrial transformation and upgrading, vigorously promoting the development of modern service industry, promoting the transformation and upgrading of processing and manufacturing industry and the rise of emerging industries, making the third industry of Guangdong show a unique performance in the whole country. The third industry is closely related to the level of regional logistics development, and the rapid development of the tertiary industry is conducive to the continuous improvement of logistics level. The correlation between the turnover of goods and the volume of logistics freight in Guangdong Province is relatively small. We need to strengthen the level of the tertiary industry development and improve the development capacity of regional logistics.

\section{Reference}

1. Heejoo Ham, Tsehangho John Kim, David Boyee. Assessment of economic impacts from unexpected events with an interregional commodity transportation network[J]. Transportation Research Part A: Policy and Pratice, 2005, 39(10): p849-860.

2. Donald J, Bowersox etc. 21st Century logistics: Making Supply Chain Integration aReality[J]. Oak Brook, IL: Council of Logistics Management 1999, 52(1): 45-54.

3. Maciulis A.Vasiliauskas A V. The Impact of transport on competitiveness of National Economy[J]. Transport.2009, 24(2): 93-99.

4. Xiao Jing, Dong Qingxue. A study on the economic factors of regional logistics development based on grey correlation analysis $[\mathrm{J}]$. Journal of Changchun University, 2017 (1): 15-19.
5. Gao Sheng, Zhang Xifeng. Grey correlation analysis of influencing factors of regional logistics development in Zhejiang Province [J]. Railway transportation and economy, 2013 (9): 49-53.

6. Rong Luqing. Research on regional waterway freight transport development based on grey prediction and grey correlation $[\mathrm{J}]$. Journal of Beijing Jiaotong University (SOCIAL SCIENCE EDITION), 2018 (2): 109-116.

7. Liu Sifeng, Party Yao Guo, fangzhigeng, et al. Grey system theory and its application [M]. Beijing: Science Press, 2010. 